Original Research Paper

\title{
Some Aspects of the Structure of Planar Mechanisms
}

\author{
${ }^{1}$ Relly Victoria Virgil Petrescu, ${ }^{2}$ Raffaella Aversa, ${ }^{3}$ Bilal Akash, \\ ${ }^{4}$ Taher M. Abu-Lebdeh, ${ }^{2}$ Antonio Apicella and ${ }^{1}$ Florian Ion Tiberiu Petrescu

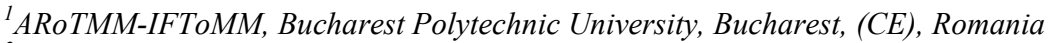 \\ ${ }^{2}$ Advanced Material Lab, Department of Architecture and Industrial Design, \\ Second University of Naples, 81031 Aversa (CE), Italy \\ ${ }^{3}$ Dean of School of Graduate Studies and Research, American University of Ras Al Khaimah, UAE \\ ${ }^{4}$ North Carolina A and T State University, USA
}

Article history

Received: 25-01-2018

Revised: 31-01-2018

Accepted: 08-02-2018

Corresponding Author: Florian Ion Tiberiu Petrescu ARoTMM-IFToMM, Bucharest Polytechnic University, Bucharest, (CE), Romania Email: scipub02@gmail.com

\begin{abstract}
The machine is a technical system made up of distinct kinematic component parts (called kinematic elements) which, following the imprinting of movements imposed on an element or elements (considered as leading elements), cause movements to all other kinematic elements in order to execute a useful mechanical thing, or transforming some form of energy into mechanical energy. It follows from the previous definition, three essential characteristics of the machine: the machine is a technical system; its kinematic elements have determined (desmodromic) movements; either to perform either a useful mechanical thing, calling it a lucrative machine, or transforming some form of energy into mechanical energy, bearing the name of a motor car. The lucrative machines are cars, locomotives, motor wagons, presses, machine tools, pumps, compressors, agricultural machines, lifting and transporting machines, etc. The motor vehicles are external combustion (Stirling, Watt) or internal combustion engines (Lenoir, Otto, Diesel, Wankel, star), turbines, hydraulic motors, reaction engines, pneumatic motors, electromagnetic), ionic engines, energy beam or LASER motors, etc. The most used mechanisms in machine building were and still maintain those that operate in a plane or in parallel planes. For this reason, new analytical methods have been developed and developed to determine all the essential aspects of these mechanisms in order to improve the design of machine components. For this reason, it is necessary to present a general presentation of the mechanism of the design of the mechanisms, the present paper dealing only with the first aspect, namely the structure of the planar mechanisms. The most common mechanisms are planar, with bars, toothed, with cams, with a mortar cross, with chains, with belts, with tracks, with bolts, with liquids (hydraulic or sonic), with air (pneumatic). However, spacecraft with universal cardan shaft (universal joint) and cardanic transmission, with hyperboloidal gears (with cross axles), with pivots (spherical couplings), especially steering and suspension mechanisms, tripod mechanisms, mechanisms with space cams, screw and nut mechanisms, robots, serial and parallel systems, steppers, etc. The mechanism, as we have already shown, is composed of kinematic elements connected by kinematic joints (or couplings).
\end{abstract}

Keywords: Machines, Mechanisms, Industrial Robots, Automation, TTT Manipulator, Design, Joints or Couplings, Structure, Elements

\section{Introduction}

The machine is a technical system made up of distinct kinematic component parts (called kinematic elements) which, following the imprinting of movements imposed on an element or elements (considered as leading elements), cause movements to all other kinematic elements in order to execute a useful 
mechanical thing, or transforming some form of energy into mechanical energy. It follows from the previous definition, three essential characteristics of the machine:

- The machine is a technical system

- Its kinematic elements have determined (desmodromic) movements

- Either to perform either a useful mechanical thing, calling it a lucrative machine, or transforming some form of energy into mechanical energy, bearing the name of a motor car

The lucrative machines are cars, locomotives, motor wagons, presses, machine tools, pumps, compressors, agricultural machines, lifting and transporting machines, etc.

The motor vehicles are external combustion (Stirling, Watt) or internal combustion engines (Lenoir, Otto, Diesel, Wankel, star), turbines, hydraulic motors, reaction engines, pneumatic motors, electromagnetic), ionic engines, energy beam or LASER motors, etc.

Note: Engines may also be classified as lucrative machines, but only complex ones (complex work machines) called aggregates.

The development and diversification of machines and mechanisms with applications in all fields requires new scientific researches for the systematization and improvement of existing mechanical systems by creating new mechanisms adapted to modern requirements, which involve increasingly complex topological structures.

The modern industry, the practice of designing and building machinery is increasingly based on the results of scientific and applied research.

Each industrial achievement has backed theoretical and experimental computer-assisted research, which solves increasingly complex problems with advanced computing programs using increasingly specialized software (Aversa et al., 2016a; 2016b; 2016c; 2016d; 2017a; 2017b; 2017c; 2017d; Mirsayar et al., 2017; Cao et al., 2013; Dong et al., 2013; De Melo et al., 2012; Garcia et al., 2007; Garcia-Murillo et al., 2013; He et al.,

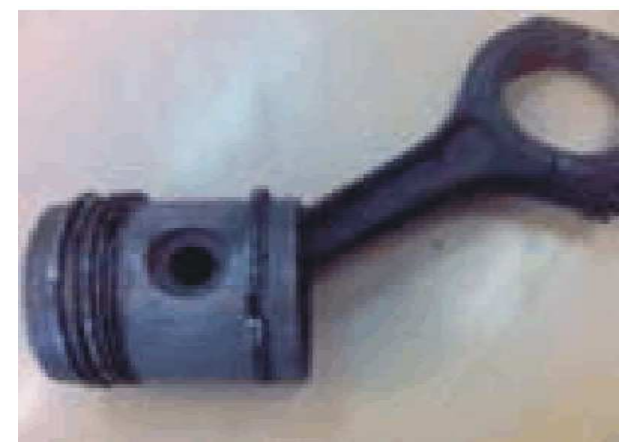

(a)
2013; Lee, 2013; Lin et al., 2013; Liu et al., 2013; Padula and Perdereau, 2013; Perumaal and Jawahar, 2013; Petrescu and Petrescu, 1995a; 1995b; 1997a; $1997 \mathrm{~b} ; 1997 \mathrm{c} ; 2000 \mathrm{a} ; 2000 \mathrm{~b} ; 2002 \mathrm{a} ; 2002 \mathrm{~b} ; 2003$; $2005 \mathrm{a} ; 2005 \mathrm{~b} ; 2005 \mathrm{c} ; 2005 \mathrm{~d} ; 2005 \mathrm{e}, 2016 \mathrm{a}$; 2016b; 2016c; 2016d; 2016e; 2013; 2012a; 2012b; 2011; Petrescu et al., 2009; 2016 a-e; 2017a; 2017b; 2017c; 2017d; 2017e; 2017f; 2017g; 2017h; 2017i; 2017j; $2017 \mathrm{k} ; 2017 \mathrm{l}$; 2017m; 2017n; 2017o; 2017p; 2017q; $2017 \mathrm{r} ; 2017 \mathrm{~s} ; 2017 \mathrm{t} ; 2017 \mathrm{u} ; 2017 \mathrm{v} ; 2017 \mathrm{w} ; 2017 \mathrm{x}$; 2017y; 2017z; 2017aa; 2017ab; 2017ac; 2017ad; 2017ae; Petrescu and Calautit, 2016a; 2016b; Reddy et al., 2012; Tabaković et al., 2013; Tang et al., 2013; Tong et al., 2013; Wang et al., 2013; Wen et al., 2012; Antonescu and Petrescu, 1985; 1989; Antonescu et al., 1985a; 1985b; 1986; 1987; 1988; 1994; 1997; 2000a; 2000b; 2001).

The mechanism is a technical system consisting of distinct kinematic component parts (called kinematic elements), which have determinate and periodic movements, intended to transmit and/or transform the initial motion (given by one or more input elements) to the final element(s).

The mechanism thus fulfills the first two essential characteristics of the machine.

Mechanisms can be operated either separately or as devices included in winch machines or engines.

It should be noted that a machine generally contains several mechanisms.

The mechanism has kinematic elements and kinematic couplings.

Below are some mechanisms.

The most common mechanisms are planar, with bars, toothed, with cams, with a mortar cross, with chains, with belts, with tracks, with bolts, with liquids (hydraulic or sonic), with air (pneumatic). However, spacecraft with universal cardan shaft (universal joint) and cardanic transmission, with hyperboloidal gears (with cross axles), with pivots (spherical couplings), especially steering and suspension mechanisms, tripod mechanisms, mechanisms with space cams, screw and nut mechanisms, robots, serial and parallel systems, steppers, etc.

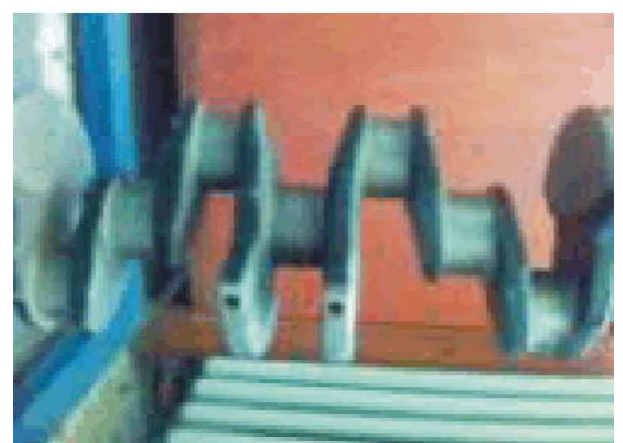

(b)

Fig. 1: Mobile components of a thermal engine 


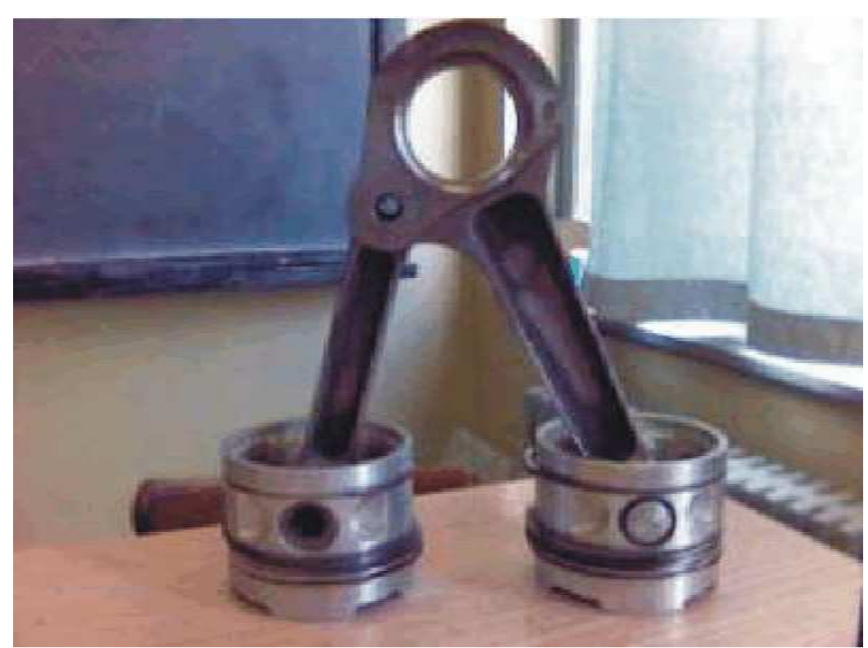

Fig. 2: Components of a $\mathrm{V}$ engine

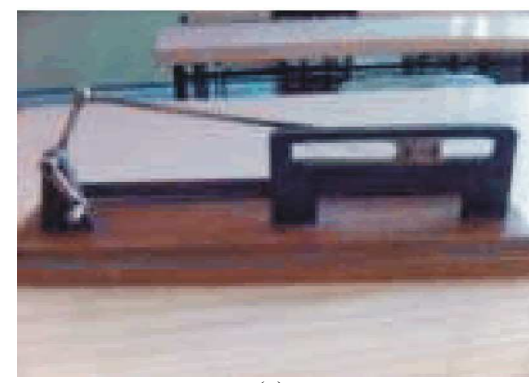

(a)

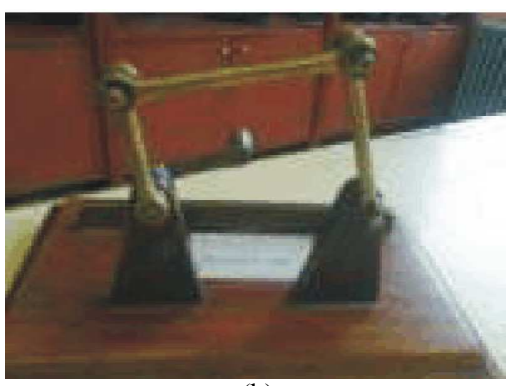

(b)

Fig. 3: Bar mechanisms: (a) mec. piston; (b) mec. quadrilateral

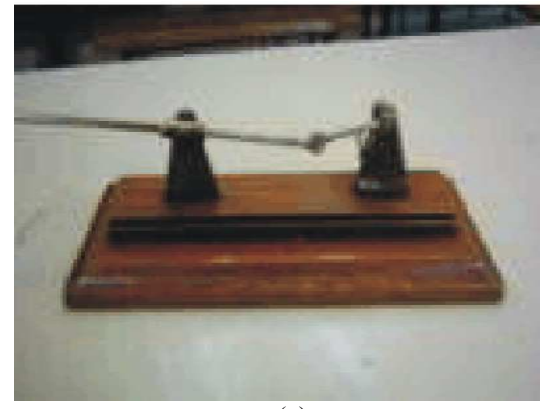

(a)

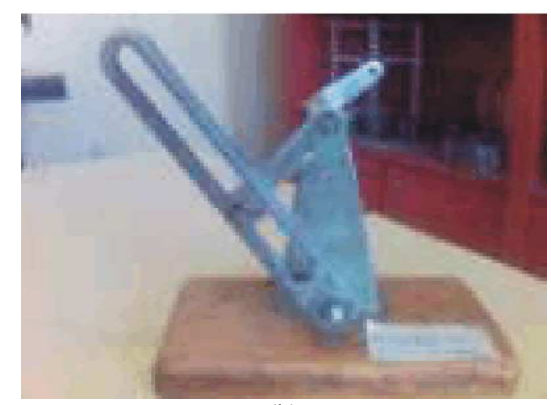

(b)

Fig. 4: Flat plane mechanisms with bars: (a) mec. with swinging rod; (b) mec. slide swing

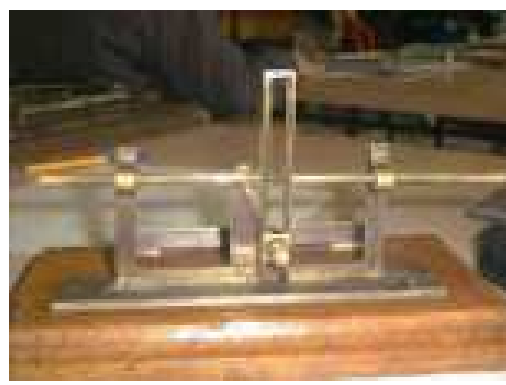

(a)

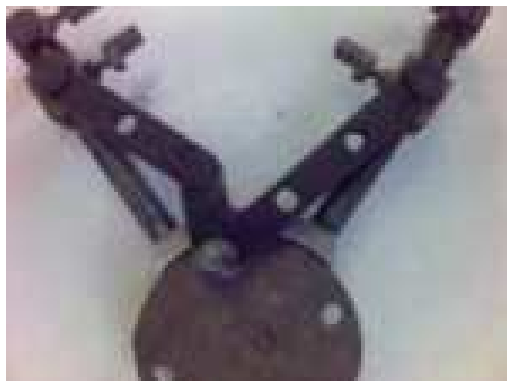

(b)

Fig. 5: (a) mecanismul transportor cu cruce; (b) mecanismul unui motor clasic în V 
Figure 1a shows the pin connected to the piston (via a bolt) and Fig. 1b shows the engine shaft (or crank) which together constitutes the three movable elements of a thermal motor or compressor. In Fig. 2 we can see the main part of a classic engine crank in $\mathrm{V}$ (missing crankshaft).

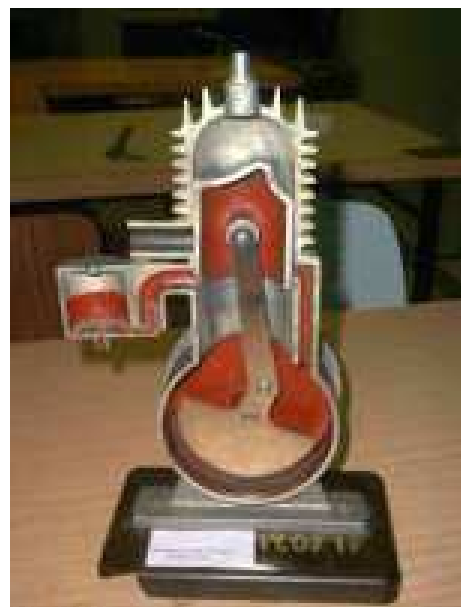

(a)
In Fig. 3 there are presented two flat bars: (a) The whip-crank-piston mechanism; (b) planar (or articulated) quadrilateral mechanism.

In Fig. 4 there are presented two other planar mechanisms with bars: (a) The oscillating rod mechanism; (b) oscillating slide mechanism.

Fig. 6: (a) the mechanism of a Lenoir engine (two-stroke engine); (b) the mechanism of a classic gearshift (manual)

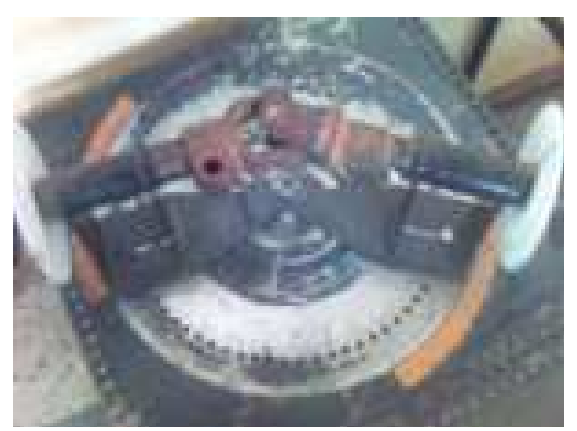

(a)

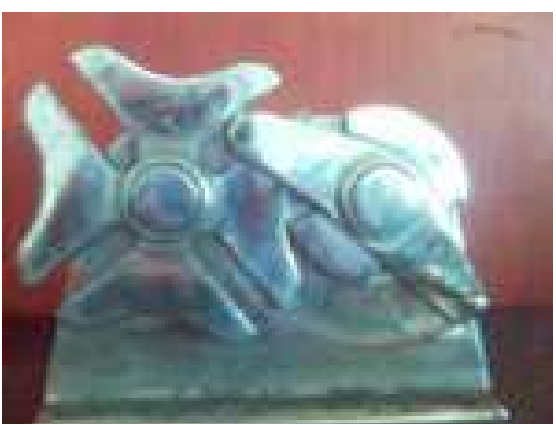

(b)

Fig. 7: (a) Cardan or universal joint mechanism (the cardan cross); (b) The two-beginner Malta cross crossing mechanism

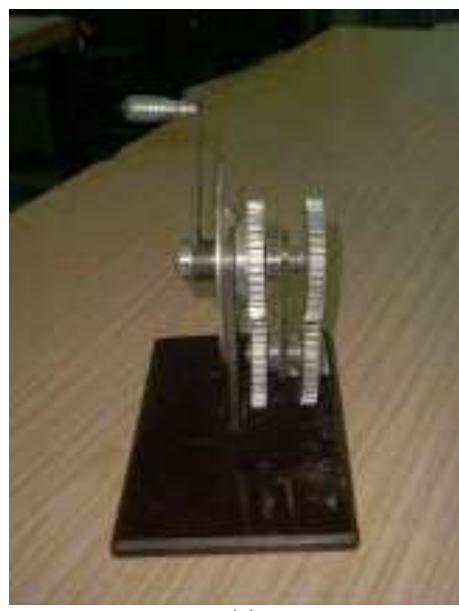

(a)

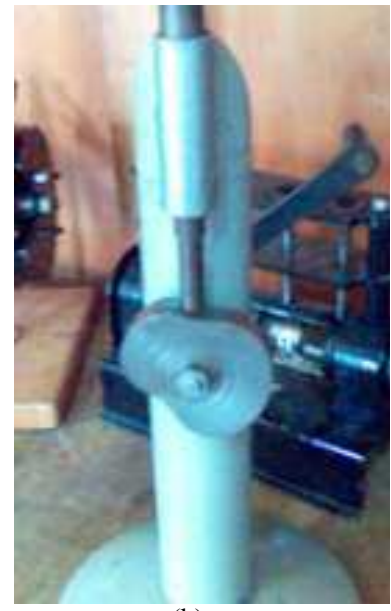

(b)

Fig. 8: (a) planetary mechanism; (b) rotating cam mechanism and translatable stick 
In Fig. 5, two other flat bars are presented: (a) The cross conveyor mechanism; (b) Engine mechanism in V.

In Fig. 6, two other mechanisms are presented: (a) The mechanism of a Lenoir engine (two-stroke engine); (b) Mechanism of a classic gearshift (manual).

In Fig. 7, two other mechanisms are presented: (a) Cardan or universal joint mechanism (cardan cross); (b) The two-beginner Malta cross crossing mechanism.

In Fig. 8 two other mechanisms are presented: (a) the planetary mechanism; (b) the rotary cam mechanism and the translatable bar.

\section{Materials and Methods}

The mechanism, as we have already shown, is composed of kinematic elements connected by kinematic joints (or couplings).

Definition: "The kinematic couple is the permanent, direct and mobile link between two kinematic elements."

The classification of kinematic couplings can be done according to four main criteria: Geometric, cinematic, constructive and structural.

\section{The Geometric Criterion}

Geometrically, there are inferior and superior kinematic couplings.

The lower kinematic couplers are those where the contact between the elements is made on a surface. This surface may be cylindrical, conical, spherical, planar, helical, etc.

The lower kinematic couplers are reversible, the surfaces in contact being geometrically identical, the relative movement of the elements not changing regardless of which of them is fixed or movable, conducting or driven.

The higher kinematic couplers are those where the contact between the elements is made by a line or a point. The line may be straight or curved (arc of circle).

The higher kinematic couplers are irreversible. The best example is that of the wheel rail coupler (Fig. 9).

In case the rail 2 is fixed and the wheel 1 rolls the contact point I will describe the cyclode $\mathrm{C} 12$. If wheel 1 is fixed and rail 2 rolls, contact I will describe the evolution of E21 (Antonescu, 2000).

\section{The Kinematic Criterion}

From a cinematic point of view, we distinguish planar couplings and space couplings.

The planar kinematic couplets allow component elements only for plane movements (in one plane, or in several parallel planes between them).

Spatial kinematic couples allow spatial movement of space elements (there is at least one point that cannot be framed by moving it in only one plane).

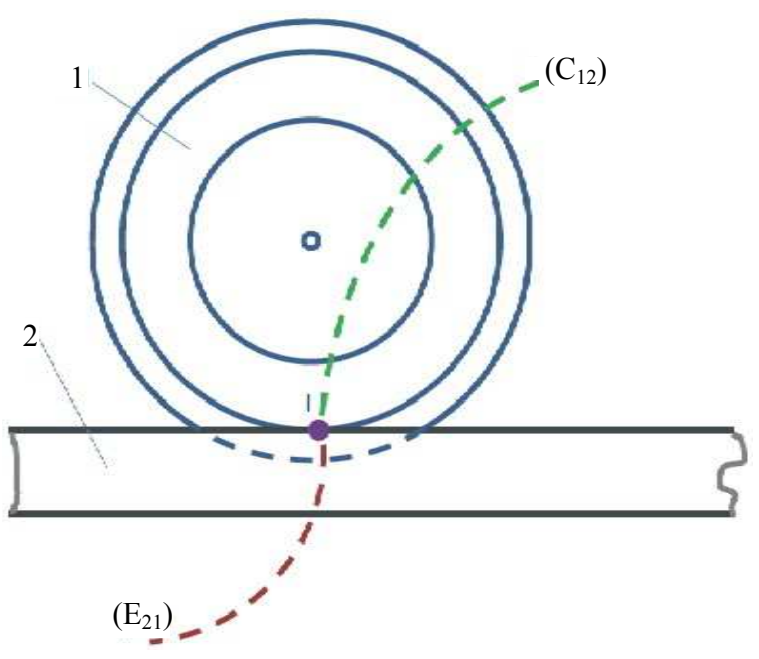

Fig. 9: High-wheel-rail superior coupling

\section{Constructive Criterion}

From a constructive point of view, the closed kinematic couplers and open cinematic couplings are distinguished.

Closed kinematic couplers are those in which the coupling of the coupling elements is made by steer guidance and the two coupling elements can not be separated without dismantling or breaking.

Open kinematic couplers are those where contact between the coupling elements is made directly by external forces (weight, electromagnetic, voltage, elastic, etc.) and the two coupling elements can be easily and directly separated without dismantling or breaking.

\section{Structural Criterion}

Structurally, kinematic couples are divided into five classes, depending on the number of degrees of freedom abducted, C1-C5.

If we denote the number of degrees of relative freedom that the kinematic coupler permits $(l=1,5)$ and with $\mathrm{k}$ the number of stopped movements (restricted by coupling), $(k=1,5)$, we can write the relations (1):

$\left\{\begin{array}{l}l+k=6 \\ l=6-k \\ k=6-l\end{array}\right.$

The kinematic coupling class will be given by $k$ (number of restrictions imposed by the coupling).

For Class 1 couples, which have a single restriction and 5 freedoms, the sphere coupling in the upper (space, open, C1) plane is shown. For second-class couples, we have the sphere in the cylinder (upper, space, closed, C2) and the cylinder on the plane (upper, space, open, C2). At third class couples, we have the 
sphere in the sphere (lower, space, closed, C3), the sphere in the cylinder, with a finger (upper, space, closed, C3) and plane (lower, flat).

In fourth class couplings, we have a torch that guides another torch (upper, space, closed, C4) and cylinder in the cylinder (lower, space, closed, C4). Here too we can remember the upper couplers with cams, toothed wheels, with a bolt, a cross from Malta, a universal or universal joint (Fig. 10), the tripods (planetary ones, Fig. 12), the Thompson coupler (Fig. 11) with constant speed, or ball (Fig. 13), etc.

For fifth class couplings, we have the rotation coupler (lower, flat, closed, C5) and the translation coupler (lower, flat, closed, C5). However, we can also remember the nutnut coupling (Fig. 14).

By definition, kinematic couples bind two kinematic elements between them, but no less than two.

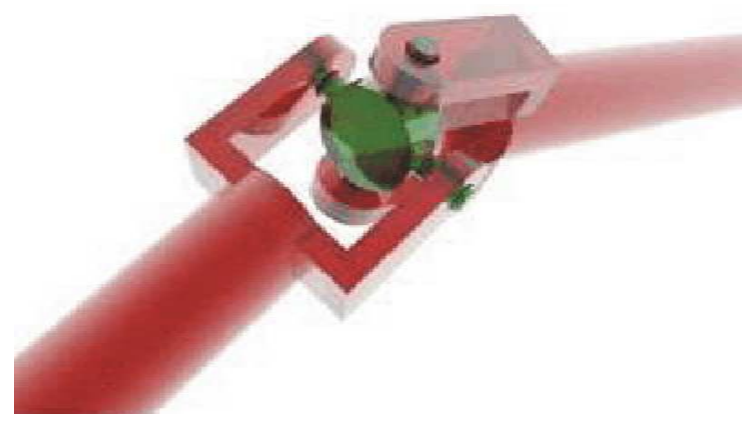

Fig. 10: Cardan cross or universal joint

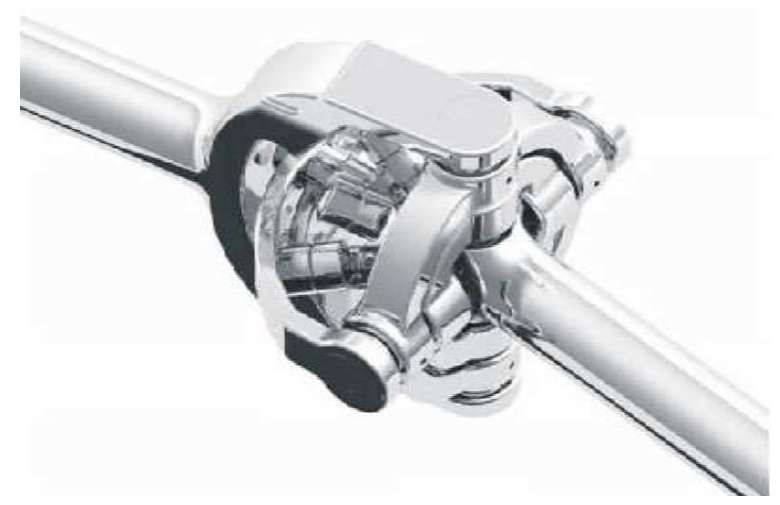

Fig. 11: The Thompson couple
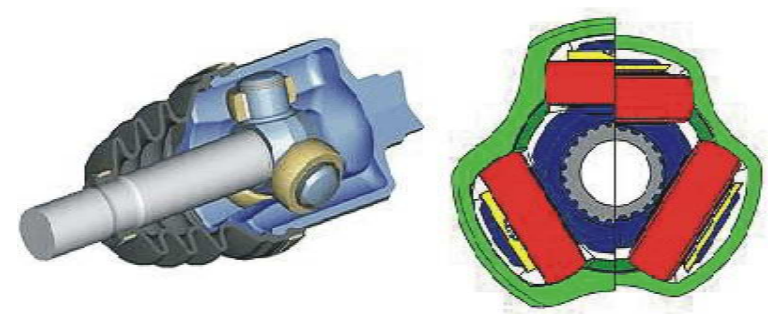

Fig. 12: The tripod couple
In some classifications, therefore, normal couplings are called simple and complex (or compound or multicouple) are referred to as couplers that violate the definition consisting of multiple elements, but also from multiple links. Such a coupling has always p-1 bonds and $\mathrm{p}$ elements and has the radial elements (in parallel, Fig. 15a), in series (Fig. 15b), or mixed (Atkinson et al., 1986). It is considered to be a single composite couple and it analyzes all its movements given by the freedoms gathered from all the simple component couplings (Fig. 16). Thus, the coupling of Fig. 16 is composed of four distinct kinematic elements and three simple couplings. In the table in Fig. 17 are presented the axonometric constructive schematic of the elementary couplings.

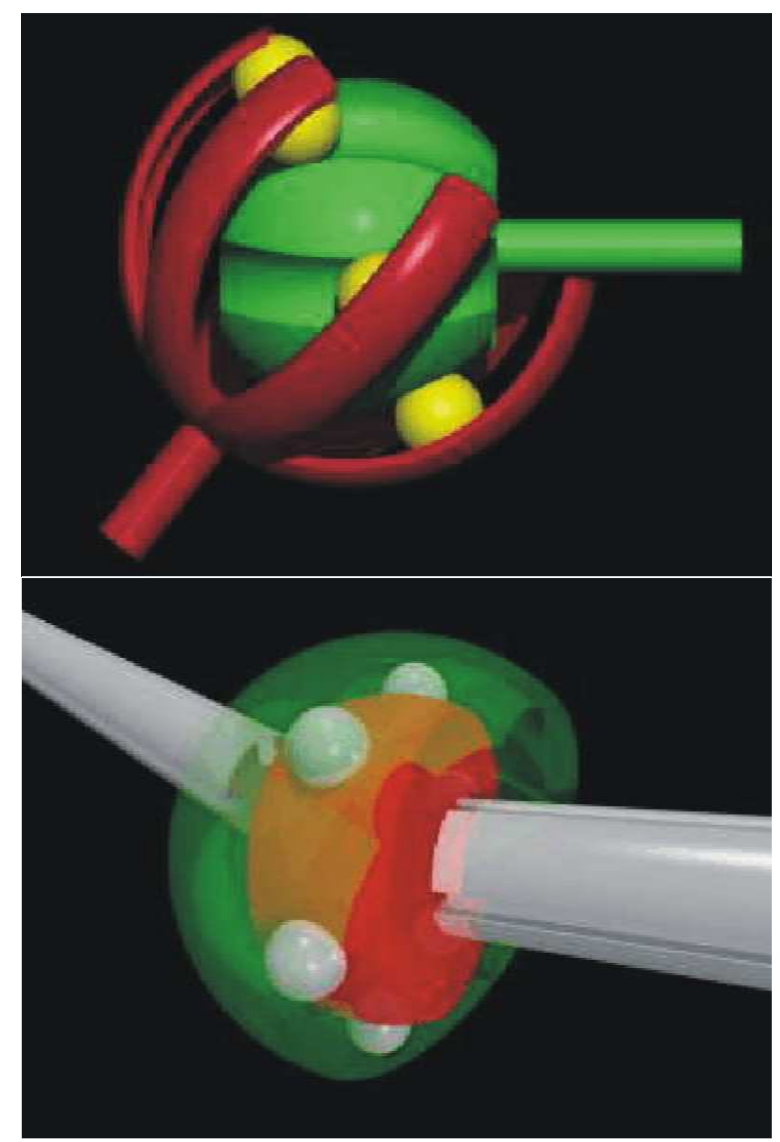

Fig. 13: Constant speed coupling (ball coupling)

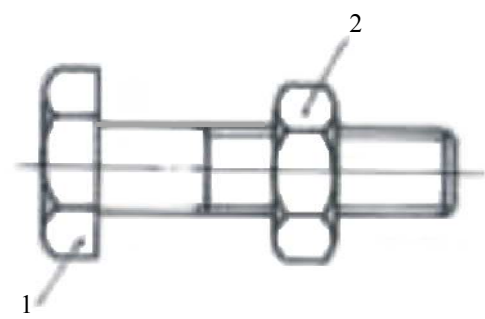

Fig. 14: Screw-nut coupling 


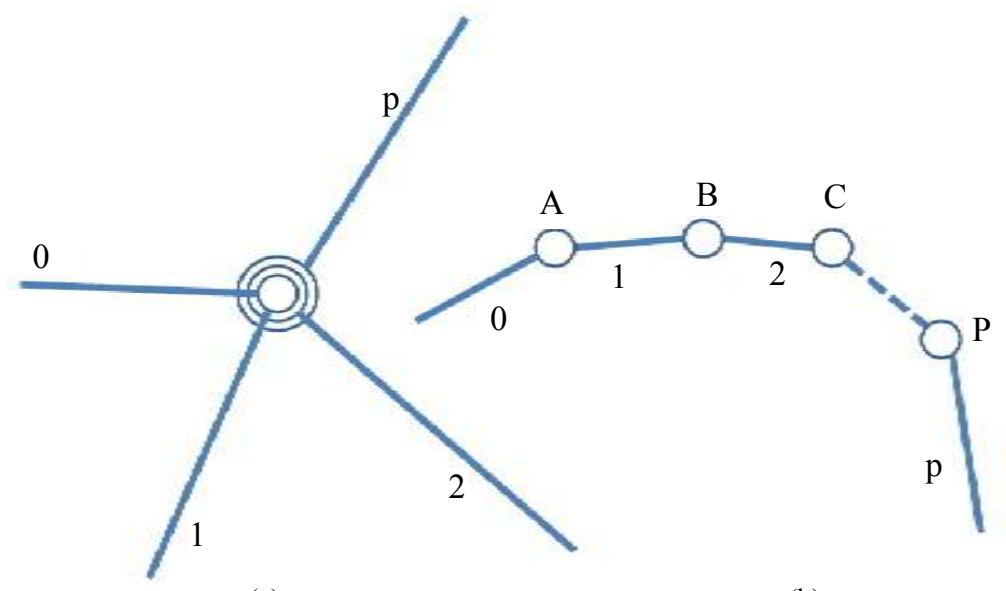

(a)

(b)

Fig. 15: Complex couplers

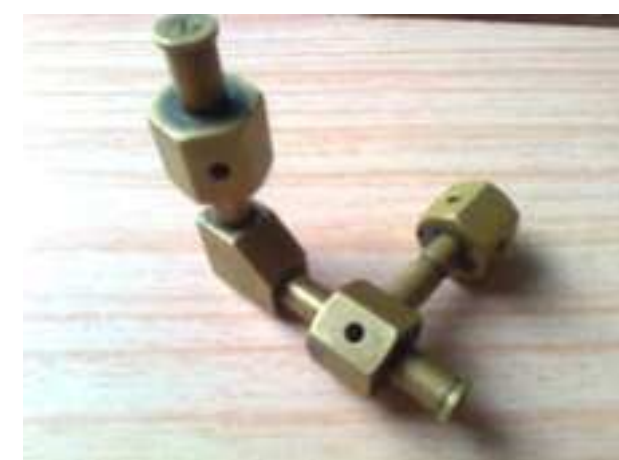

Fig. 16: Complex couplers

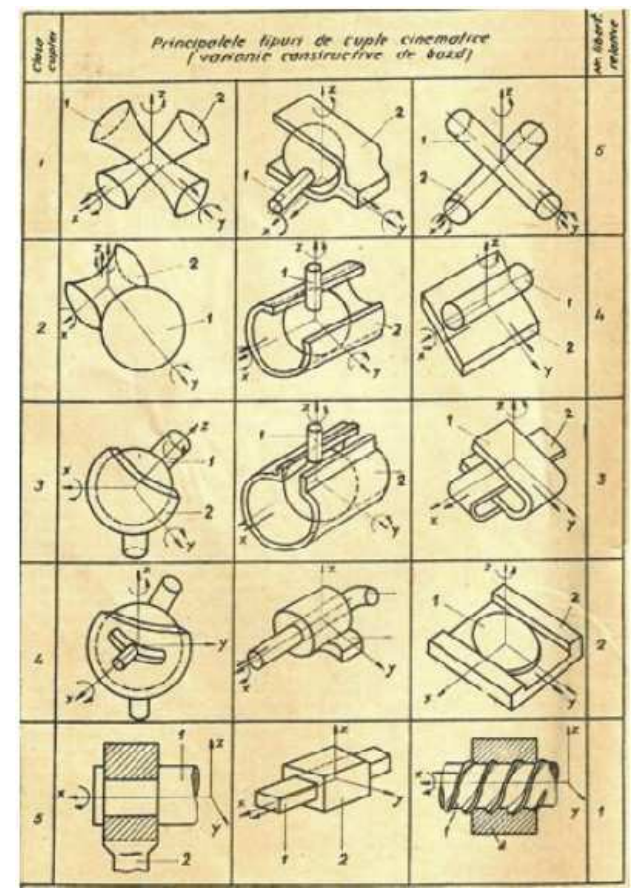

Fig. 17: Table with axonometric constructive representations of elementary couplings

\section{Results}

The structural analysis of plane mechanisms will be followed, being the most common mechanisms. It is intended to determine the mode of formation of the mechanism, specifying the number and type of component kinematic elements and couplings, the degree of mobility of the mechanism, as well as the class to which it belongs (for this purpose the kinematic scheme, the structural scheme and the block diagram or connections).

Figure 18a shows a schematic diagram of a planar mechanism with bars. Figure $18 \mathrm{~b}$ shows the kinematic schematics of the planar mechanism in Fig. 1, a simplified scheme that helps to study the mechanism (cinematic, structural, cinetostatic, dynamic, etc ...).

In Fig. 19 shows how to determine kinematic elements starting from the leading element 1 which performs a complete rotation (crank movement) and in Fig. 20, the kinematic coupler of the mechanism is identified and the complete kinematic schema with identified kinematic elements and kits will appear in Fig. 21.

The kinematic elements and couplings have already been intuitively identified on the drawing so that the tables of the couplings and the kinematic elements can easily be drawn, showing how each coupling is formed by connecting two elements (the resulting fifth-class coupling, which can be rotation - R or translation - T), but also how many links each element has (see table in Fig. 22).

The degree of mobility of the planar bar mechanism is determined by formula (2):

$$
\begin{aligned}
& M_{3}=3 \cdot m-2 \cdot C_{5}-C_{4}=3 \cdot m-2 \cdot i-s \\
& =3 \cdot 7-2 \cdot 10-0=21-20-0=1
\end{aligned}
$$

where, $m$ is the number of movable elements (in the present case $m=7$ ), $C_{5}=i=$ the number of fifth or fifth 
class couplings, comprising both the $R$ and the $R$ couplers (for the given mechanism $i=10$ ) and $C_{4}=s$ represents the number of fourth or upper class

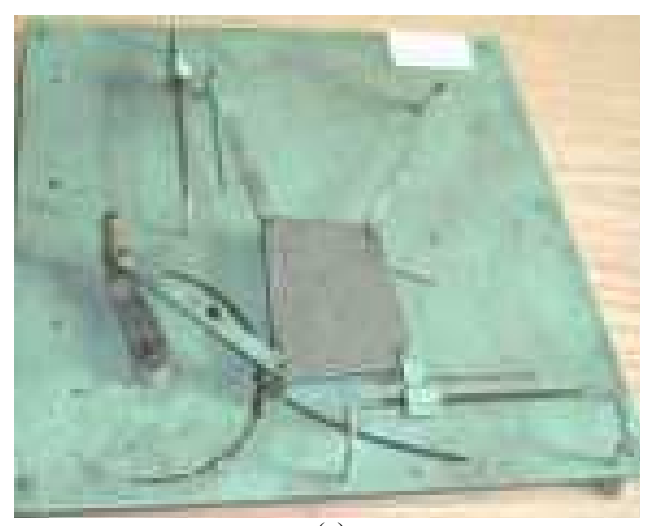

(a) couplings (camshaft couplings, toothed gears, Malta cross, contact profiles, etc.), (in the case of the upper coupler not present, $\mathrm{s}=0$ ).

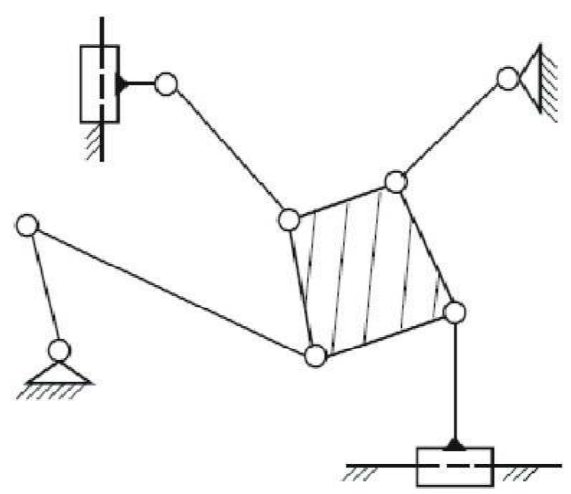

(b)

Fig. 18: (a) Schematic drawing of the planar mechanism with bars (b) The kinematic scheme of the mechanism

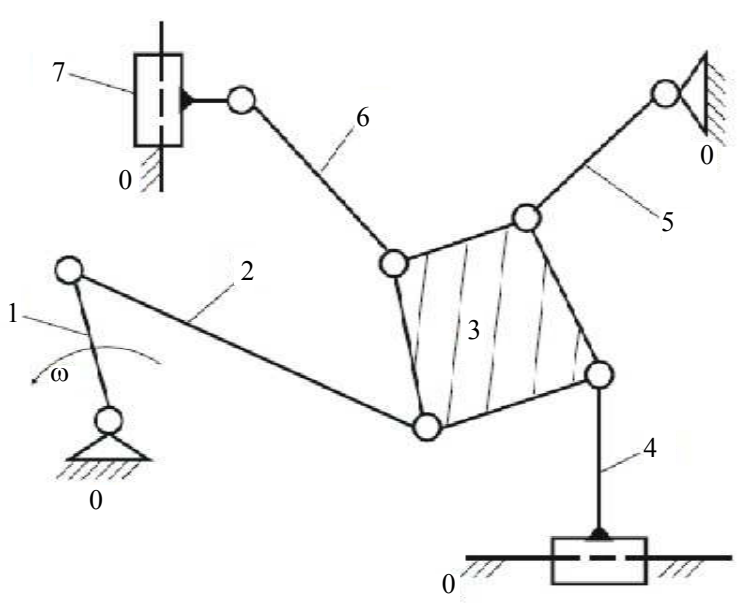

Fig. 19: How to determine kinematic elements starting from the leading element 1

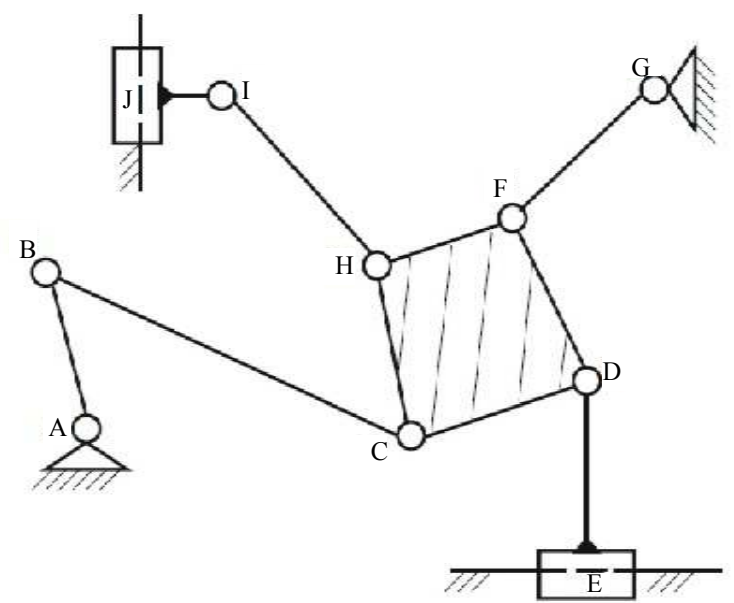

Fig. 20: The kinematic coupler of the mechanism is identified

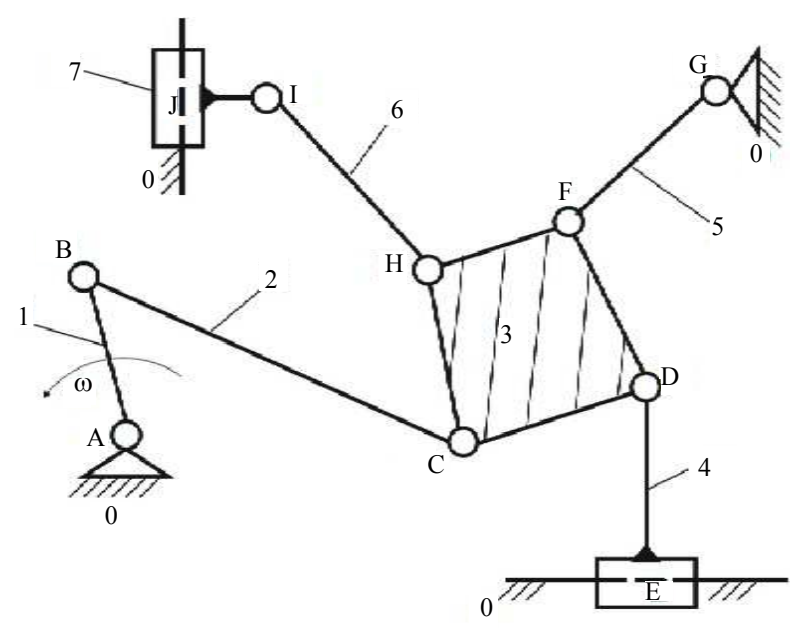

Fig. 21: The complete kinematic schema

\begin{tabular}{|c|c|c|}
\hline \multirow{2}{*}{ Couple table } & \multicolumn{2}{|c|}{ Elements table } \\
\hline & \multirow{2}{*}{$0(\mathrm{~A}, \mathrm{E}, \mathrm{G}, \mathrm{J}) \mathrm{IV}$} & \\
\hline $\mathrm{A}(0,1) \mathrm{R}$ & & \\
\hline $\mathrm{B}(1,2) \mathrm{R}$ & \multirow[b]{2}{*}{ 1(A,B)II } & \multirow[b]{2}{*}{$A \circ \longrightarrow B$} \\
\hline $\mathrm{C}(2,3) \mathrm{R}$ & & \\
\hline $\mathrm{D}(3,4) \mathrm{R}$ & 2(B,C)II & $\mathrm{B} \circlearrowleft \mathrm{C}$ \\
\hline $\mathrm{E}(4,0) \mathrm{T}$ & \multirow{2}{*}{$3(\mathrm{C}, \mathrm{D}, \mathrm{F}, \mathrm{H}) \mathrm{IV}$} & \multirow{2}{*}{${ }_{D}^{\mathrm{Cq}} \mathrm{d}_{\mathrm{F}}^{\mathrm{H}}$} \\
\hline $\mathrm{F}(3,5) \mathrm{R}$ & & \\
\hline $\mathrm{G}(5,0) \mathrm{R}$ & \multirow[b]{2}{*}{$5(\mathrm{~F}, \mathrm{G}) \mathrm{II}$} & $\mathrm{D} \circ \mathrm{OE}$ \\
\hline $\mathrm{H}(3,6) \mathrm{R}$ & & $\mathrm{F} O \longrightarrow \mathrm{G}$ \\
\hline $\mathrm{I}(6,7) \mathrm{R}$ & & \\
\hline $\mathrm{J}(7,0) \mathrm{T}$ & $6(\mathrm{H}, \mathrm{I}) \mathrm{II}$ & $\mathrm{H} \odot \mathrm{O}$ \\
\hline & 7(I,J)II & $\mathrm{I} \circlearrowleft \mathrm{J}$ \\
\hline
\end{tabular}

Fig. 22: The kinematic elements and couplings 


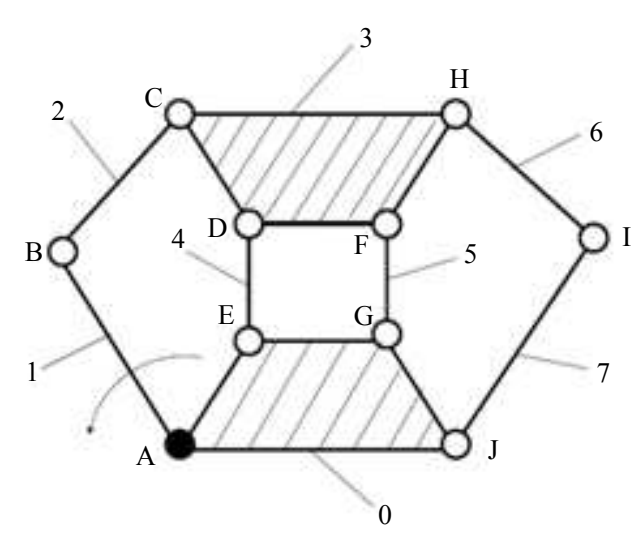

Fig. 23: The structural scheme of the mechanism

The structural diagram of the mechanism is built from the kinematic element table. It starts from the fixed element (0). After drawing it with the potential kinematic couplers (in the present case A, E, G, J), the first movable kinematic element (element 1) is attached to the frame, taking care to match the coupler A from the frame to that of element 1 Add the coupling B to it; then stick the elements 2, 3, 4 and 5 always matching the respective couplers. Add items 6 and 7; all kinematic elements and couplings are noted, after which the structural diagram is ready (see Fig. 23). Important observation: In the structural scheme, all the couplings are inferior (after the kinematic equation of the upper ones) and all are equally circular, as if only rotating, even if some of them are translation. Active couplers (motors) are black.

The mechanism connection scheme (Fig. 25) consists of rectangular blocks connected to each other. Goes to block 0 , representing the fixed element that has only output buttons (A, E, G, J). The first linked button is A, which represents both the output of block 0 and the input to block 1 (EC driver element, or ME element moto). For 1 button $\mathrm{B}$ is output and for triad $(2,3,4,5)$ it is input, just like the buttons $(\mathrm{E}$ and $\mathrm{G})$. The triad has three inputs $(\mathrm{B}$, $\mathrm{E}, \mathrm{G})$ and three inner couplings $(\mathrm{C}, \mathrm{D}, \mathrm{F})$; An output coupler $\mathrm{H}$ is added, which becomes an inlet coupling for diada D $(6,7)$, just like the coupling $\mathrm{J}$ coming out of the frame. Diada always has two input couplers (in this case, $\mathrm{H}$ and $\mathrm{J}$ ) and an inner coupler (at the given mechanism, coupling I). No diaphragm $(6,7)$ is added to any output coupler so that the mechanism is fully studied.

Determining the structural formula is done using the structural scheme (divided into structural groups), or by using the connection scheme.

For the exemplary mechanism the structural formula reads.

$\mathrm{Z}(0)+\mathrm{EC}(1)+\mathrm{T}(2,3,4,5)+\mathrm{D}(6,7)$ or $\mathrm{Z}(0)+\mathrm{ME}$ (1) $(6,7)$ or $\mathrm{MF}(0,1)+\mathrm{T}(2,3,4,5)+\mathrm{D}(6,7)$, i.e., zero pole + Guide element 1 (Moto Element), 1) to which triad $\mathrm{T}(2,3,4,5)$ and diada $\mathrm{D}(6,7)$ are added.

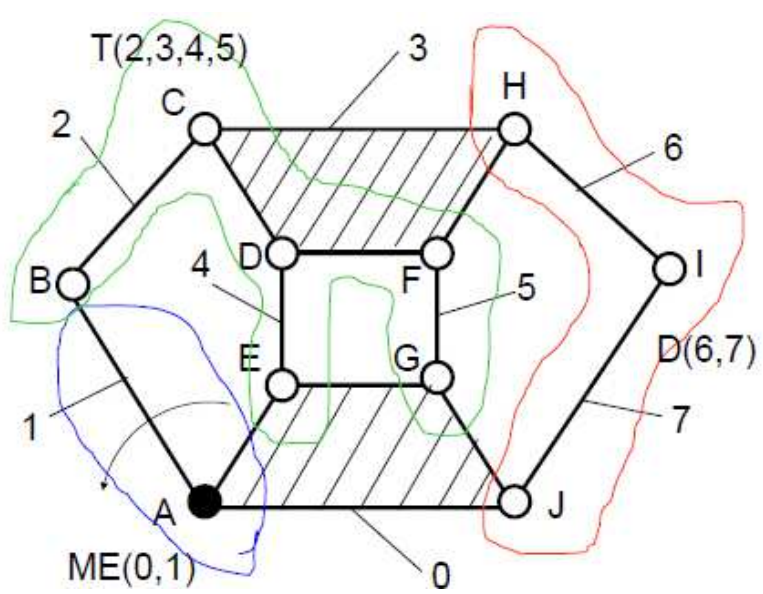

Fig. 24: The structural scheme of the bar mechanism divided into the structural groups: One can see a triad $\mathrm{T}$ $(2,3,4,5)$ and a dyad D $(6,7)$

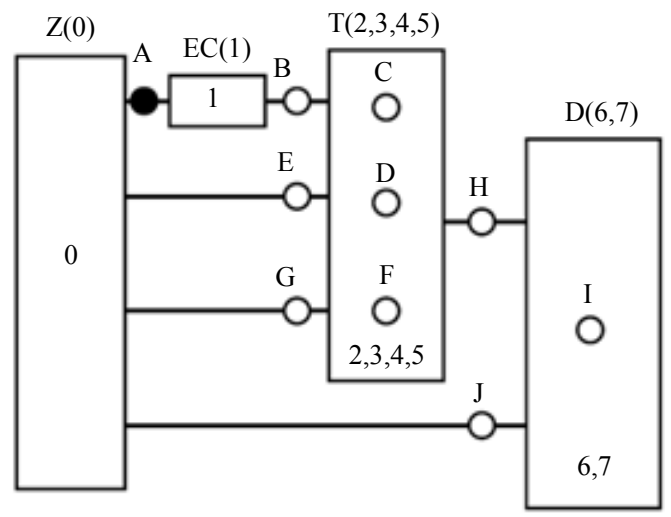

Fig. 25: Scheme of connection of the mechanism

The simplest structural group is diada.

A structural group (or Assuric) must not change the degree of mobility of the mechanism to which it is added; in other words the structural group has the degree of mobility equal to zero. For Flat Mechanisms, flat structural groups are used, which are synthesized according to the structural formula.

After equating the higher kinematic couplers, the formula takes the form (3):

$3 \cdot m-2 \cdot i=0$

In Table 1 we give a few pairs of numbers that satisfy the relation (3), pairs by which the flat Assurice structural groups, containing only the couplers $i$, will be constructed.

The simplest structural group is dyad (see the first cell in Fig. 26). It consists of two kinematic elements (both of which have the rank II, that is, both the element 1 of length $\mathrm{AB}$ and the element 2 of length $\mathrm{BC}$ each have only two kinematic couplings, so each is of the order II). 
In any structural group, the class of the group is given by the highest deformable closed contour, or by the highest ranked kinematic element.

There is no outline in the diadem, so its class is given by the highest rank element. Since both elements of a dyad have the second rank, it follows that the dyad class is also II.

The order of a structural group is given by the input couple of the group, couples which are also called semi couples or potential couples (since they only conclude when the structural group links to a mechanism).

Each structural group has $(\mathrm{a}+\mathrm{b})$ couplings:

- Inputs (semi couples) (they give the order of the group)

- inner couplings

- Output couplers (semi couples); these can be added in unlimited number or even absent, they are not represented on the definition of a structural group, they are added but are not part of the respective structural group

Diada has two input (potential) couplings, (in Fig. 26, marked with A and B), so the order of any dyad is 2 .

Each diadem also has an inner coupler (in the table in Fig. 26, it is marked with C).

In conclusion, the dyad is the simplest class II class of the 2nd order, having 2 elements and three couplings (two of which are semi couples because they are the input and the third is the inner one).

Table 1: Pairs of numbers that satisfy the relationship (3)

\begin{tabular}{lllll}
\hline $\mathrm{M}$ & 2 & 4 & 6 & $\ldots$ \\
$\mathrm{i}$ & 3 & 6 & 9 & $\ldots$ \\
\hline
\end{tabular}

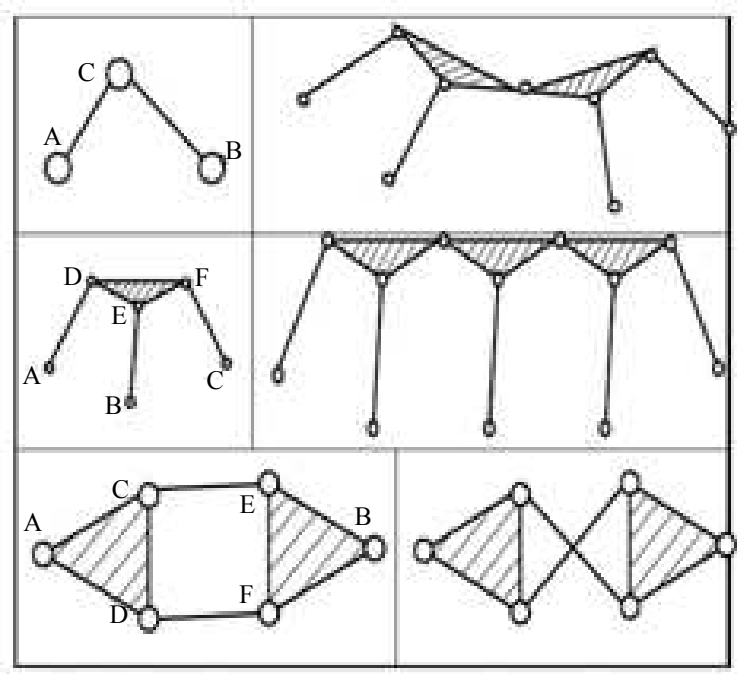

Fig. 26: Several schemes of simple (usual) structural groups
In the table of Fig. 26, the triad is immediately below the diadem. It has four elements and six kinematic couplings, of which 3 (three) are external input couplers $(\mathrm{A}, \mathrm{B}, \mathrm{C})$ and three are inner couplers $(\mathrm{D}, \mathrm{E}, \mathrm{F})$. The triad does not have any deformable contour, so its class will be given by the highest rank element. As it has three elements of rank II and one of rank III (triangle), it follows that any simple triad has the third class.

The order of the triad is given by the input couples (three in number), so the triad has the order 3.

Also, with four movable elements and six couplings, another structural group, namely tetrad, can be constructed (see the entire column on the left, the third row in the table in Fig. 26).

Tetrada has a definite deformable contour of IV, so it is a class IV class structure.

Since four couplings are internal and only two inputs (A and B), the tetrad is of the order 2 .

In the same table on the right of the tetrad can be seen a tetrad in the cross, which is also the fourth class, the 2nd order.

In row 1 , the second column, you can see a double triad (with 6 elements and 9 cups), it is also class III, but of the 4 th order.

Below it is a triple triad (with 8 elements and 12 couplings), with a 3 rd order, 5 th order.

There are also pentas, hexas, etc ... but the usual ones are only: Dyad, triad or double triad and normal tetrad or a cross tetrad.

\section{Discussion}

For the mechanisms with five movable kinematic elements and a fixed one with one driving element (motor) two types of structural schemes can be obtained: (James) Watt (Fig. 27) or (George) Stephenson (Fig. 28).

However, we choose the fixed and leader elements in the Watt scheme to obtain two dyads. On the Stephenson scheme, we can get two dyads, but we can reach a triad if we choose the fixed and leading elements in a certain way (for example, in the structural scheme of Fig. 28, the movable element 5 must be chosen as the leading element, triad 1,2,3,4).

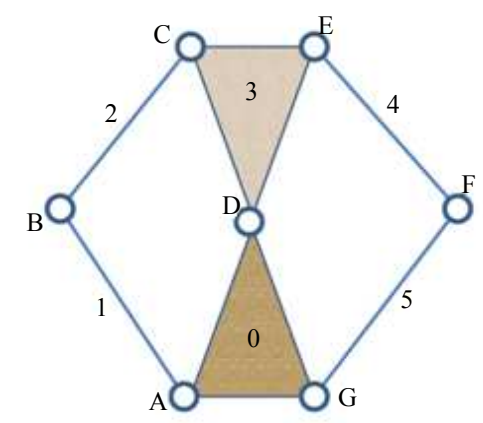

Fig. 27: Watt structural diagram 


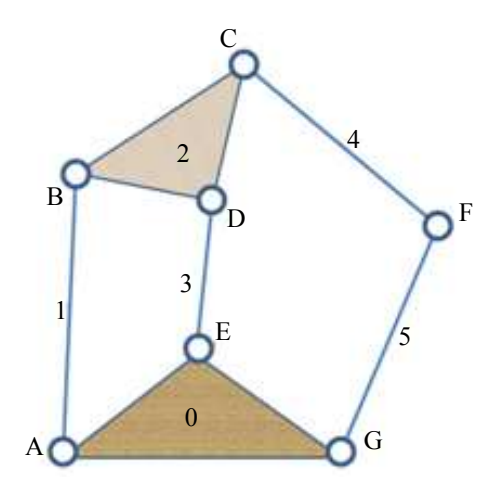

Fig. 28: Stephenson Structural Scheme

\section{Conclusion}

The machine is a technical system made up of distinct kinematic component parts (called kinematic elements) which, following the imprinting of movements imposed on an element or elements (considered as leading elements), cause movements to all other kinematic elements in order to execute a useful mechanical thing, or transforming some form of energy into mechanical energy. It follows from the previous definition, three essential characteristics of the machine: The machine is a technical system; its kinematic elements have determined (desmodromic) movements; either to perform either a useful mechanical thing, calling it a lucrative machine, or transforming some form of energy into mechanical energy, bearing the name of a motor car.

The lucrative machines are cars, locomotives, motor wagons, presses, machine tools, pumps, compressors, agricultural machines, lifting and transporting machines, etc. The motor vehicles are external combustion (Stirling, Watt) or internal combustion engines (Lenoir, Otto, Diesel, Wankel, star), turbines, hydraulic motors, reaction engines, pneumatic motors, electromagnetic), ionic engines, energy beam or LASER motors, etc.

The most used mechanisms in machine building were and still maintain those that operate in a plane or in parallel planes. For this reason, new analytical methods have been developed and developed to determine all the essential aspects of these mechanisms in order to improve the design of machine components. For this reason, it is necessary to present a general presentation of the mechanism of the design of the mechanisms, the present paper dealing only with the first aspect, namely the structure of the planar mechanisms.

The most common mechanisms are planar, with bars, toothed, with cams, with a mortar cross, with chains, with belts, with tracks, with bolts, with liquids (hydraulic or sonic), with air (pneumatic).

However, spacecraft with universal cardan shaft (universal joint) and cardanic transmission, with hyperboloidal gears (with cross axles), with pivots (spherical couplings), especially steering and suspension mechanisms, tripod mechanisms, mechanisms with space cams, screw and nut mechanisms, robots, serial and parallel systems, steppers, etc.

The mechanism, as we have already shown, is composed of kinematic elements connected by kinematic joints (or couplings).

\section{Acknowledgement}

This text was acknowledged and appreciated by Dr. Veturia CHIROIU Honorific member of Technical Sciences Academy of Romania (ASTR) PhD supervisor in Mechanical Engineering.

\section{Funding Information}

Research contract: 1-Research contract: Contract number 36-5-4D/1986 from 24IV1985, beneficiary CNST RO (Romanian National Center for Science and Technology) Improving dynamic mechanisms.

2-Contract research integration. 19-91-3 from 29.03.1991; Beneficiary: MIS; TOPIC: Research on designing mechanisms with bars, cams and gears, with application in industrial robots.

3-Contract research. GR 69/10.05.2007: NURC in 2762; theme 8: Dynamic analysis of mechanisms and manipulators with bars and gears.

4-Labor contract, no. 35/22.01.2013, the UPB, "Stand for reading performance parameters of kinematics and dynamic mechanisms, using inductive and incremental encoders, to a Mitsubishi Mechatronic System" "PNIIIN- CI-2012-1-0389".

All these matters are copyrighted! Copyrights: $394-$ qodGnhhtej, from 17-02-2010 13:42:18; 463vpstuCGsiy, from 20-03-2010 12:45:30; 631sqfsgqvutm, from 24-05-2010 16:15:22; 933CrDztEfqow, from 07-01-2011 13:37:52.

\section{Author's Contributions}

All the authors contributed equally to prepare, develop and carry out this manuscript.

\section{Ethics}

This article is original and contains unpublished material. Authors declare that are not ethical issues and no conflict of interest that may arise after the publication of this manuscript.

\section{References}

Antonescu, P., 2000. Mechanisms and handlers. Printech Publishing House, Bucharest. 
Antonescu, P. and F. Petrescu, 1985. Analytical method of synthesis of cam mechanism and flat stick. Proceedings of the 4th International Symposium on Mechanism Theory and Practice, (TPM' 85), Bucharest.

Antonescu, P. and F. Petrescu, 1989. Contributions to cinetoelastodynamic analysis of distribution mechanisms. Bucharest.

Antonescu, P., M. Oprean and F. Petrescu, 1985a. Contributions to the synthesis of oscillating cam mechanism and oscillating flat stick. Proceedings of the 4th International Symposium on Theory and Practice of Mechanisms, (TPM' 85), Bucharest.

Antonescu, P., M. Oprean and F. Petrescu, 1985b. At the projection of the oscillante cams, there are mechanisms and distribution variables. Proceedings of the V-Conference for Engines, Automobiles, Tractors and Agricultural Machines, I-Engines and Automobiles, (AMA’ 85), Brasov.

Antonescu, P., M. Oprean and F. Petrescu, 1986. Projection of the profile of the rotating camshaft acting on the oscillating plate with disengagement. Proceedings of the 3rd National Computer Assisted Designing Symposium in Mechanisms and Machine Bodies, (MOM' 86), Brasov.

Antonescu, P., M. Oprean and F. Petrescu, 1987. Dynamic analysis of the cam distribution mechanisms. Proceedings of the 7 th National Symposium of Industrial Robots and Spatial Mechanisms, (IMS' 87), Bucharest.

Antonescu, P., M. Oprean and F. Petrescu, 1988 Analytical synthesis of Kurz profile, rotating flat cam cam. Mach. Build. Rev. Bucharest.

Antonescu, P., F. Petrescu and O. Antonescu, 1994. Contributions to the synthesis of the rotating cam mechanism and the tip of the balancing tip. Brasov.

Antonescu, P., F. Petrescu and D. Antonescu, 1997. Geometrical synthesis of the rotary cam and balance tappet mechanism. Bucharest.

Antonescu, P., F. Petrescu and O. Antonescu, 2000a. Contributions to the synthesis of the rotary disc-cam profile. Proceedings of the 8th International Conference on Theory of Machines and Mechanisms, (TMM’ 00), Liberec, Czech Republic, pp: 51-56.

Antonescu, P., F. Petrescu and O. Antonescu, 2000b. Synthesis of the rotary cam profile with balance follower. Proceedings of the 8th Symposium on Mechanisms and Mechanical Transmissions, (MMT'000), Imişoara, pp: 39-44.

Antonescu, P., F. Petrescu and O. Antonescu, 2001. Contributions to the synthesis of mechanisms with rotary disc-cam. Proceedings of the 8th IFToMM International Symposium on Theory of Machines and Mechanisms, (TMM' 01), Bucharest, ROMANIA, pp: 31-36.
Atkinson, C., Chae H.A. and J. Hollerbach, 1986. Estimation of inertial parameters of manipulator loads and links. Int. J. Robot. Res., 5: 101-119. DOI: $10.1177 / 027836498600500306$

Aversa, R., R.V. Petrescu, A. Apicella and F.I.T. Petrescu, 2017a. Nano-diamond hybrid materials for structural biomedical application. Am. J. Biochem. Biotechnol., 13: 34-41.

DOI: 10.3844/ajbbsp.2017.34.41

Aversa, R., R.V. Petrescu, B. Akash, R.B. Bucinell and J.M. Corchado et al., 2017b. Kinematics and forces to a new model forging manipulator. Am. J. Applied Sci., 14: 60-80. DOI: 10.3844/ajassp.2017.60.80

Aversa, R., R.V. Petrescu, A. Apicella, F.I.T. Petrescu and J.K. Calautit et al., 2017c. Something about the $\mathrm{V}$ engines design. Am. J. Applied Sci., 14: 34-52. DOI: 10.3844/ajassp.2017.34.52

Aversa, R., D. Parcesepe, R.V. Petrescu, F. Berto and G. Chen et al., 2017d. Processability of bulk metallic glasses. Am. J. Applied Sci., 14: 294-301. DOI: 10.3844/ajassp.2017.294.301

Aversa, R., F.I.T. Petrescu, R.V. Petrescu and A. Apicella, 2016a. Biomimetic FEA bone modeling for customized hybrid biological prostheses development. Am. J. Applied Sci., 13: 1060-1067. DOI: 10.3844/ajassp.2016.1060.1067

Aversa, R., D. Parcesepe, R.V. Petrescu, G. Chen and F.I.T. Petrescu et al., 2016b. Glassy amorphous metal injection molded induced morphological defects. Am. J. Applied Sci., 13: 1476-1482. DOI: 10.3844 /ajassp.2016.1476.1482

Aversa, R., R.V. Petrescu, F.I.T. Petrescu and A. Apicella, 2016c. Smart-factory: Optimization and process control of composite centrifuged pipes. Am. J. Applied Sci., 13: 1330-1341.

DOI: 10.3844/ajassp.2016.1330.1341

Aversa, R., F. Tamburrino, R.V. Petrescu, F.I.T. Petrescu and M. Artur et al., $2016 \mathrm{~d}$. Biomechanically inspired shape memory effect machines driven by muscle like acting NiTi alloys. Am. J. Applied Sci., 13: 1264-1271. DOI: 10.3844/ajassp.2016.1264.1271

Cao, W., H. Ding, Z. Bin and C. Ziming, 2013. New structural representation and digital-analysis platform for symmetrical parallel mechanisms. Int. J. Adv. Robot. Sys. DOI: 10.5772/56380

Dong, H., N. Giakoumidis, N. Figueroa and N. Mavridis, 2013. Approaching behaviour monitor and vibration indication in developing a General Moving Object Alarm System (GMOAS). Int. J. Adv. Robot. Sys. DOI: $10.5772 / 56586$

De Melo, L.F., S.F. Rosário and J.M. Rosário, 2012. Mobile robot navigation modelling, control and applications. Int. Rev. Modell. Simulat., 5: 1059-1068. 
Garcia, E., M.A. Jimenez, P.G. De Santos and M. Armada, 2007. The evolution of robotics research. IEEE Robot. Autom. Magaz., 14: 90-103. DOI: 10.1109/MRA.2007.339608

Garcia-Murillo, M., J. Gallardo-Alvarado and E. Castillo-Castaneda, 2013. Finding the generalized forces of a series-parallel manipulator. IJARS. DOI: $10.5772 / 53824$

He, B., Z. Wang, Q. Li, H. Xie and R. Shen, 2013. An analytic method for the kinematics and dynamics of a multiple-backbone continuum robot. IJARS. DOI: $10.5772 / 54051$

Lee, B.J., 2013. Geometrical derivation of differential kinematics to calibrate model parameters of flexible manipulator. Int. J. Adv. Robot. Sys. DOI: $10.5772 / 55592$

Lin, W., B. Li, X. Yang and D. Zhang, 2013. Modelling and control of inverse dynamics for a 5-DOF parallel kinematic polishing machine. Int. J. Adv. Robot. Sys. DOI: 10.5772/54966

Liu, H., W. Zhou, X. Lai and S. Zhu, 2013. An efficient inverse kinematic algorithm for a PUMA560structured robot manipulator. IJARS. DOI: $10.5772 / 56403$

Mirsayar, M.M., V.A. Joneidi, R.V. Petrescu, F.I.T. Petrescu and F. Berto, 2017. Extended MTSN criterion for fracture analysis of soda lime glass. Eng. Fracture Mechan., 178: 50-59. DOI: 10.1016/j.engfracmech.2017.04.018

Padula, F. and V. Perdereau, 2013. An on-line path planner for industrial manipulators. Int. J. Adv. Robot. Sys. DOI: 10.5772/55063

Perumaal, S. and N. Jawahar, 2013. Automated trajectory planner of industrial robot for pickandplace task. IJARS. DOI: 10.5772/53940

Petrescu, F. and R. Petrescu, 1995a. Contributions to optimization of the polynomial motion laws of the stick from the internal combustion engine distribution mechanism. Bucharest.

Petrescu, F. and R. Petrescu, 1995b. Contributions to the synthesis of internal combustion engine distribution mechanisms. Bucharest.

Petrescu, F. and R. Petrescu, 1997a. Dynamics of cam mechanisms (exemplified on the classic distribution mechanism). Bucharest.

Petrescu, F. and R. Petrescu, 1997b. Contributions to the synthesis of the distribution mechanisms of internal combustion engines with Cartesian coordinate method. Bucharest.

Petrescu, F. and R. Petrescu, 1997c. Contributions to maximizing polynomial laws for the active stroke of the distribution mechanism from internal combustion engines. Bucharest.
Petrescu, F. and R. Petrescu, 2000a. Synthesis of distribution mechanisms by the rectangular (Cartesian) coordinate method. University of Craiova, Craiova.

Petrescu, F. and R. Petrescu, 2000b. The design (synthesis) of cams using the polar coordinate method (the triangle method). University of Craiova, Craiova.

Petrescu, F. and R. Petrescu, 2002a. Motion laws for cams. Proceedings of the 7th National Symposium with International Participation Computer Assisted Design, (PAC' 02), Braşov, pp: 321-326.

Petrescu, F. and R. Petrescu, 2002b. Camshaft dynamics elements. Proceedings of the 7th National Symposium with International Participation Computer Assisted Design, (PAC' 02), Braşov, pp: 327-332.

Petrescu, F. and R. Petrescu, 2003. Some elements regarding the improvement of the engine design. Proceedings of the 8th National Symposium, Descriptive Geometry, Technical Graphics and Design, (GTD’ 03), Braşov, pp: 353-358.

Petrescu, F. and R. Petrescu, 2005a. The cam design for a better efficiency. Proceedings of the International Conference on Engineering Graphics and Design, (EGD’ 05), Bucharest, pp: 245-248.

Petrescu, F. and R. Petrescu, 2005b. Contributions at the dynamics of cams. Proceedings of the 9th IFToMM International Symposium on Theory of Machines and Mechanisms, (MM' 05), Bucharest, Romania, pp: 123-128.

Petrescu, F. and R. Petrescu, 2005c. Determining the dynamic efficiency of cams. Proceedings of the 9th IFToMM International Symposium on Theory of Machines and Mechanisms, (MM' 05), Bucharest, Romania, pp: 129-134.

Petrescu, F. and R. Petrescu, 2005d. An original internal combustion engine. Proceedings of the 9th IFToMM International Symposium on Theory of Machines and Mechanisms, (TMM' 05), Bucharest, Romania, pp: 135-140.

Petrescu, F. and R. Petrescu, 2005e. Determining the mechanical efficiency of Otto engine's mechanism. Proceedings of the 9th IFToMM International Symposium on Theory of Machines and Mechanisms, (MM' 05), Bucharest, Romania, pp: 141-146.

Petrescu, F.I. and R.V. Petrescu, 2013. Cinematics of the 3R Dyad. ENGEVISTA, 15: 118-124.

Petrescu, F.I. and R.V. Petrescu, 2012a. Kinematics of the planar quadrilateral mechanism. ENGEVISTA, 14: 345-348.

Petrescu, F.I. and R.V. Petrescu, 2012b MecatronicaSisteme Seriale si Paralele. 1st Edn., Create Space Publisher, USA, ISBN-10: 978-1-4750-6613-5, pp: 128.

Petrescu, F.I. and R.V. Petrescu, 2011. Mechanical Systems, Serial and Parallel-Course (in Romanian). 1st Edn., LULU Publisher, London, UK, ISBN-10: 978-1- 4466-0039-9, pp: 124. 
Petrescu, F.I. and R.V. Petrescu, 2016a. Parallel moving mechanical systems kinematics. ENGEVISTA, 18: 455-491.

Petrescu, F.I. and R.V. Petrescu, 2016b. Direct and inverse kinematics to the anthropomorphic robots. ENGEVISTA, 18: 109-124.

Petrescu, F. and R. Petrescu, 2016c. An otto engine dynamic model. IJM\&P, 7: 038-048.

Petrescu, F.I. and R.V. Petrescu, 2016e. Dynamic cinematic to a structure 2R. GEINTEC, 6: 3143-3154.

Petrescu, 2009. Some mechanical design elements. Proceeding of the International Conference on Computational Mechanics and Virtual Engineering, (MEC' 09), Braşo, pp: 520-525.

Petrescu, R.V., R. Aversa, A. Apicella, M.M. Mirsayar and F.I.T. Petrescu, 2016a. About the gear efficiency to a simple planetary train. Am. J. Applied Sci., 13: 1428-1436. DOI: 10.3844 ajassp.2016.1428.1436

Petrescu, R.V., R. Aversa, A. Apicella, S. Li and G. Chen et al., 2016b. Something about electron dimension. Am. J. Applied Sci., 13: 1272-1276. DOI: 10.3844/ajassp.2016.1272.1276

Petrescu, F.I.T., A. Apicella, R. Aversa, R.V. Petrescu and J.K. Calautit et al., 2016c. Something about the mechanical moment of inertia. Am. J. Applied Sci., 13: $1085-1090$.

DOI: 10.3844/ajassp.2016.1085.1090

Petrescu, R.V., R. Aversa, A. Apicella, F. Berto and S. Li et al., 2016d. Ecosphere protection through green energy. Am. J. Applied Sci., 13: 1027-1032. DOI: 10.3844 /ajassp.2016.1027.1032

Petrescu, F.I.T., A. Apicella, R.V. Petrescu, S.P. Kozaitis and R.B. Bucinell et al., $2016 \mathrm{e}$. Environmental protection through nuclear energy. Am. J. Applied Sci., 13: 941-946. DOI: 10.3844 /ajassp.2016.941.946

Petrescu, F.I.T. and J.K. Calautit, 2016a. About nano fusion and dynamic fusion. Am. J. Applied Sci., 13: 261-266. DOI: 10.3844/ajassp.2016.261.266

Petrescu, F.I.T. and J.K. Calautit, 2016b. About the light dimensions. Am. J. Applied Sci., 13: 321-325. DOI: 10.3844/ajassp.2016.321.325

Petrescu, R.V., R. Aversa, B. Akash, R. Bucinell and J. Corchado et al., 2017a. Modern propulsions for aerospace-a review. J. Aircraft Spacecraft Technol., 1: 1-8. DOI: 10.3844 /jastsp.2017.1.8

Petrescu, R.V., R. Aversa, B. Akash, R. Bucinell and J. Corchado et al., 2017b. Modern propulsions for aerospace-part II. J. Aircraft Spacecraft Technol., 1: 9-17. DOI: 10.3844/jastsp.2017.9.17

Petrescu, R.V., R. Aversa, B. Akash, R. Bucinell and J. Corchado et al., 2017c. History of aviation-a short review. J. Aircraft Spacecraft Technol., 1: 30-49. DOI: 10.3844 /jastsp.2017.30.49
Petrescu, R.V., R. Aversa, B. Akash, R. Bucinell and J. Corchado et al., 2017d. Lockheed martin-a short review. J. Aircraft Spacecraft Technol., 1: 50-68. DOI: 10.3844 jastsp.2017.50.68

Petrescu, R.V., R. Aversa, B. Akash, J. Corchado and F. Berto et al., 2017e. Our universe. J. Aircraft Spacecraft Technol., 1: 69-79. DOI: 10.3844/jastsp.2017.69.79

Petrescu, R.V., R. Aversa, B. Akash, J. Corchado and F. Berto et al., 2017f. What is a UFO? J. Aircraft Spacecraft Technol., 1: 80-90. DOI: $10.3844 /$ jastsp.2017.80.90

Petrescu, R.V., R. Aversa, B. Akash, J. Corchado and F. Berto et al., 2017g. About bell helicopter FCX-001 concept aircraft-a short review. J. Aircraft Spacecraft Technol., 1: 91-96. DOI: 10.3844/jastsp.2017.91.96

Petrescu, R.V., R. Aversa, B. Akash, J. Corchado and F. Berto et al., 2017h. Home at airbus. J. Aircraft Spacecraft Technol., 1: 97-118. DOI: 10.3844 /jastsp.2017.97.118

Petrescu, R.V., R. Aversa, B. Akash, J. Corchado and F. Berto et al., 2017i. Airlander. J. Aircraft Spacecraft Technol., 1: 119-148. DOI: 10.3844 /jastsp.2017.119.148

Petrescu, R.V., R. Aversa, B. Akash, J. Corchado and F. Berto et al., 2017j. When boeing is dreaming-a review. J. Aircraft Spacecraft Technol., 1: 149-161. DOI: $10.3844 /$ jastsp.2017.149.161

Petrescu, R.V., R. Aversa, B. Akash, J. Corchado and F. Berto et al., 2017k. About Northrop Grumman. J. Aircraft Spacecraft Technol., 1: 162-185. DOI: $10.3844 /$ jastsp.2017.162.185

Petrescu, R.V., R. Aversa, B. Akash, J. Corchado and F. Berto et al., 20171. Some special aircraft. J. Aircraft Spacecraft Technol., 1: 186-203. DOI: 10.3844 /jastsp.2017.186.203

Petrescu, R.V., R. Aversa, B. Akash, J. Corchado and F. Berto et al., $2017 \mathrm{~m}$. About helicopters. J. Aircraft Spacecraft Technol., 1: 204-223. DOI: $10.3844 /$ jastsp.2017.204.223

Petrescu, R.V., R. Aversa, B. Akash, F. Berto and A. Apicella et al., 2017n. The modern flight. J. Aircraft Spacecraft Technol., 1: 224-233. DOI: 10.3844 /jastsp.2017.224.233

Petrescu, R.V., R. Aversa, B. Akash, F. Berto and A. Apicella et al., 2017o. Sustainable energy for aerospace vessels. J. Aircraft Spacecraft Technol., 1: 234-240. DOI: 10.3844/jastsp.2017.234.240

Petrescu, R.V., R. Aversa, B. Akash, F. Berto and A. Apicella et al., 2017p. Unmanned helicopters. J. Aircraft Spacecraft Technol., 1: 241-248. DOI: $10.3844 /$ jastsp.2017.241.248

Petrescu, R.V., R. Aversa, B. Akash, F. Berto and A. Apicella et al., 2017q. Project HARP. J. Aircraft Spacecraft Technol., 1: 249-257. DOI: $10.3844 /$ jastsp.2017.249.257 
Petrescu, R.V., R. Aversa, B. Akash, F. Berto and A. Apicella et al., 2017r. Presentation of Romanian engineers who contributed to the development of global aeronautics-part I. J. Aircraft Spacecraft Technol., 1: 258-271. DOI: 10.3844 /jastsp.2017.258.271

Petrescu, R.V., R. Aversa, B. Akash, F. Berto and A. Apicella et al., 2017s. A first-class ticket to the planet mars, please. J. Aircraft Spacecraft Technol., 1: 272-281. DOI: 10.3844 /jastsp. 2017.272.281

Petrescu, R.V., R. Aversa, B. Akash, F. Berto and A. Apicella et al., 2017t. Forces of a 3R robot. J. Mechatron. Robot., 1: 1-14. DOI: $10.3844 /$ jmrsp.2017.1.14

Petrescu, R.V., R. Aversa, B. Akash, F. Berto and A. Apicella et al., 2017u. Direct geometry and cinematic to the MP-3R systems. J. Mechatron. Robot., 1: 15-23. DOI: 10.3844/jmrsp.2017.15.23

Petrescu, R.V., R. Aversa, B. Akash, F. Berto and A. Apicella et al., 2017v. Dynamic elements at MP3R. J. Mechatron. Robot., 1: 24-37. DOI: $10.3844 / \mathrm{jmrsp} .2017 .24 .37$

Petrescu, R.V., R. Aversa, B. Akash, F. Berto and A. Apicella et al., 2017w. Geometry and direct kinematics to MP3R with $4 \times 4$ operators. J. Mechatron. Robot., 1: 38-46. DOI: $10.3844 /$ jmrsp.2017.38.46

Petrescu, R.V., R. Aversa, A. Apicella, M.M. Mirsayar and S. Kozaitis et al., 2017x. Current stage in the field of mechanisms with gears and rods. J. Mechatron. Robot., 1: 47-57. DOI: $10.3844 / j \mathrm{mrsp} .2017 .47 .57$

Petrescu, R.V., R. Aversa, A. Apicella, M.M. Mirsayar and S. Kozaitis et al., 2017y. Geometry and inverse kinematic at the MP3R mobile systems. J. Mechatron. Robot., 1: 58-65. DOI: $10.3844 / \mathrm{jmrsp} .2017 .58 .65$

Petrescu, R.V., R. Aversa, A. Apicella, M.M. Mirsayar and S. Kozaitis et al., 2017z. Synthesis of optimal trajectories with functions control at the level of the kinematic drive couplings. J. Mechatron. Robot., 1: 66-74. DOI: $10.3844 /$ jmrsp.2017.66.74

Petrescu, R.V., R. Aversa, A. Apicella, M.M. Mirsayar and S. Kozaitis et al., 2017aa. The inverse kinematics of the plane system 2-3 in a mechatronic MP2R system, by a trigonometric method. J. Mechatron. Robot., 1: 75-87. DOI: $10.3844 /$ jmrsp.2017.75.87

Petrescu, R.V., R. Aversa, A. Apicella, M.M. Mirsayar and S. Kozaitis et al., 2017ab. Serial, anthropomorphic, spatial, mechatronic systems can be studied more simply in a plan. J. Mechatron. Robot., 1: 88-97. DOI: 10.3844/jmrsp.2017.88.97
Petrescu, R.V., R. Aversa, A. Apicella, M.M. Mirsayar and S. Kozaitis et al., 2017ac. Analysis and synthesis of mechanisms with bars and gears used in robots and manipulators. J. Mechatron. Robot., 1: 98-108. DOI: $10.3844 /$ jmrsp.2017.98.108

Petrescu, R.V., R. Aversa, A. Apicella, M.M. Mirsayar and S. Kozaitis et al., 2017ad. Speeds and accelerations in direct kinematics to the MP3R systems. J. Mechatron. Robot., 1: 109-117. DOI: $10.3844 /$ jmrsp.2017.109.117

Petrescu, R.V., R. Aversa, A. Apicella, M.M. Mirsayar and S. Kozaitis et al., 2017ae. Geometry and determining the positions of a plan transporter manipulator. J. Mechatron. Robot., 1: 118-126. DOI: $10.3844 /$ jmrsp.2017.118.126

Reddy, P., K.V. Shihabudheen and J. Jacob, 2012. Precise non linear modeling of flexible link flexible joint manipulator. IReMoS, 5: 1368-1374.

Tabaković, S., M. Zeljković, R. Gatalo and A. Živković, 2013. Program suite for conceptual designing of parallel mechanism-based robots and machine tools. Int. J. Adv. Robot Sys. DOI: $10.5772 / 56633$

Tang, X., D. Sun and Z. Shao, 2013. The structure and dimensional design of a reconfigurable PKM. IJARS. DOI: 10.5772/54696

Tong, G., J. Gu and W. Xie, 2013. Virtual entity-based rapid prototype for design and simulation of humanoid robots. Int. J. Adv. Robot. Sys. DOI: $10.5772 / 55936$

Wang, K., M. Luo, T. Mei, J. Zhao and Y. Cao, 2013. Dynamics analysis of a three-DOF planar serialparallel mechanism for active dynamic balancing with respect to a given trajectory. Int. J. Adv. Robotic Sys. DOI: 10.5772/54201

Wen, S., J. Zhu, X. Li, A. Rad and X. Chen, 2012. Endpoint contact force control with quantitative feedback theory for mobile robots. IJARS.

DOI: $10.5772 / 53742$ 